\title{
Microstructural design of Ni-base alloys for high-temperature applications: impact of heat treatment on microstructure and mechanical properties after selective laser melting
}

\author{
F. Brenne ${ }^{1,5} \cdot$ A. Taube ${ }^{1} \cdot$ M. Pröbstle ${ }^{2} \cdot$ S. Neumeier ${ }^{2} \cdot$ D. Schwarze ${ }^{3}$. \\ M. Schaper ${ }^{1}$ - T. Niendorf ${ }^{4,5}$
}

Received: 11 December 2015/Accepted: 15 June 2016/Published online: 5 July 2016

(C) Springer International Publishing Switzerland 2016

\begin{abstract}
Optimising the microstructure and mechanical performance of Ni-base alloys is vital to achieve higher efficiencies in many high-temperature applications. With the recent emergence of the additive manufacturing technologies, new possibilities with respect to freedom of design and microstructure manipulation are opened up. This study aims at adjusting a microstructure suited for high-temperature applications by employing high-power selective laser melting. The parts are subjected to diverse post-process heat treatments to examine if the desired microstructural features can be preserved and proper precipitations can be formed. Results obtained by electron backscatter diffraction show a high resistance against recrystallization in the temperature range contemplated. Still, process-induced formation of undesired brittle Laves phase particles was observed via transmission electron microscopy and backscattered electron imaging. Mechanical tests in the form of hardness measurements, tensile
\end{abstract}

F. Brenne

brenne@uni-kassel.de

1 Lehrstuhl für Werkstoffkunde (Materials Science),

Universität Paderborn, Warburger Straße 100,

33098 Paderborn, Germany

2 Department Materials Science and Engineering, Institute I, Friedrich-Alexander-Universität Erlangen-Nürnberg, Martensstraße 5, 91058 Erlangen, Germany

3 SLM Solutions Group AG, Roggenhorster Straße 9c, 23556 Lübeck, Germany

4 Institute of Materials Engineering, Technische Universität Bergakademie Freiberg, Gustav-Zeuner-Straße 5, 09599 Freiberg, Germany

5 Present Address: Institut für Werkstofftechnik-Metallische Werkstoffe, Universität Kassel, Mönchebergstraße 3, 34125 Kassel, Germany tests, and high-temperature compression creep tests proved a high dependency of the performance on the post-processing treatment conducted. Hardness, yield strength and elongation at failure at room temperature are adequate in comparison with conventionally processed materials. Hightemperature compression creep tests emphasised the importance of solution annealing to enable for proper precipitation of strengthening phases during subsequent ageing.

Keywords Additive manufacturing - Ni-base alloys . High-temperature applications · Microstructure .

Mechanical properties

\section{Introduction}

Processing of Ni-base alloys for use in high-temperature applications is one of the main challenges for today's manufacturing technologies. Due to their excellent corrosion resistance and high-temperature performance, such alloys are widely used in applications, such as gas turbines, rocket engines, nuclear reactors or for petrochemical equipment [1, 2]. However, traditional manufacturing routes, mostly casting, forging or conventional powder metallurgical techniques, still restrict the attainable efficiency of the parts produced. Complex geometries, for example, cannot be obtained in cast or forged parts due to poor machinability [3-5]. Parts obtained by powder metallurgy feature a rather fine-grained isotropic microstructure undesired for special applications, e.g. turbine blades, and often suffer from residual porosity, which has to be removed by additional hot isostatic pressing $[6,7]$.

With the emergence of the additive manufacturing (AM) technologies during the past decade, new possibilities are 
opened up. Due to layer-wise processing, parts of highly complex geometries become feasible, especially in the case of powder bed-based systems [8-10]. A differentiation between these systems is often made according to the energy source used for melting of the discrete powder particles, i.e. a laser in the case of selective laser melting (SLM) or an electron beam in the case of selective electron beam melting (SEBM). Although the energy source is different, many recent studies showed that both techniques are capable of processing a wide range of metallic materials, e.g., Ti-6Al-4V, 316L stainless steel, H13 tool steel, Ni-base superalloys, TWIP-steel, tantalum and aluminium [11-17]. As SLM was applied in this study, the focus will be on this technique in the remainder. However, it has to be considered that SLM and SEBM feature quite similar process characteristics-at least at low processing chamber temperatures-resulting in similar solidification mechanisms, microstructure and mechanical properties of the parts produced.

Comparing SLM with conventional processing techniques, parts of equal mechanical properties can be produced, as was shown by Leuders et al. [11] for Ti-6Al-4V subjected to different post-process treatments. Results obtained by Niendorf et al. [12] by focusing on a 316L stainless steel showed that yield strengths similar to wrought material, as given in [18], were obtained already in the asprocessed condition. This can be attributed to small grain sizes provoked by high-temperature gradients and, thus, fast solidification prevalent during SLM, as for example discussed by Thijs et al. [19]. Another study by this group revealed that in the case of additively processed tantalum, these process characteristics lead to distinct microstructural features, such as strong crystallographic texture [16]. Consequently, mechanical properties were found to be highly anisotropic. Drawing on this, recent studies examined how the microstructure can be directly manipulated by altering process parameters. In terms of scanning strategy, i.e. the direction of the laser path during exposure of each layer, the texture of an AlSi10Mg alloy was found to be controllable [17]. Other possibilities were proposed by Niendorf et al. $[12,20]$. In these studies, highly anisotropic microstructures were obtained by either applying lasers of different nominal powers or by reducing the part dimensions relative to the melt pool dimensions. In any case, the physical quantities dominating the solidification and resulting microstructures were the thermal gradient $G$ in combination with the solidification velocity $v$, as discussed in more detail by Gäumann et al. for epitaxial laser metal forming [21]. In [22] it was shown that, applying different lasers in distinct areas, fully intact parts of locally different mechanical behaviour can be directly produced.

For actual applications of Ni-base alloys, these insights might be highly beneficial. The directionally solidified microstructure of turbine blades, for example, is characterised by grains elongated in the direction of the centrifugal forces to withstand high-temperature creep during operation. Although such grains can be obtained by conventional casting routines as well, cooling channels have to be drilled in a subsequent working step. This not only implies a higher fabrication effort but also a limitation towards the complexity of the geometry and eventually a reduced efficiency. Combining the typical high design freedom of additive manufacturing with the possibility of a directly controllable microstructure, optimised parts for high-temperature applications can be obtained.

However, the mechanical properties are not only determined by the grain morphology and orientation, but also by proper precipitation of the strengthening $\gamma^{\prime}$ and $\gamma^{\prime \prime}$ phases. These are typically obtained by post-process heat treatments, e.g. in the form of solution annealing and ageing, where a concurrent recrystallisation of the microstructure is often observed [14, 23, 24]. If such precipitations can be formed after high-power SLM and if the grain structure induced by the processing parameters is preserved, still has to be answered to fully establish additive manufacturing for the production of high-temperature parts. Consequently, the current work focuses on the microstructure evolution and mechanical properties of an additively processed hightemperature alloy. A microstructure featuring elongated grains and strong texture-typically suited for high-temperature application - is induced by the use of a highpower laser and subjected to different post-process heat treatments. The impact on the resulting microstructure in terms of grain morphology, texture and precipitations as well as the relationships to the mechanical performance under both tensile load and high-temperature compression creep is examined.

\section{Experimental details}

The material investigated was Inconel 718 alloy gas atomised under argon atmosphere and finally provided in the form of spherical powder in a particle diameter range from 20 to $63 \mu \mathrm{m}$.

For manufacturing of specimens, a SLM $280^{\mathrm{HL}}$ (SLM Solutions Group AG, Lübeck, Germany) was employed. The machine is equipped with two lasers with nominal powers of $400 \mathrm{~W}$ and $1 \mathrm{~kW}$, respectively. The exposure parameters followed a Hull-Core-Strategy, with the low-power laser applied for melting the contour and the high-power laser used for exposure of the inner area of the solid rods. As the melt pool appears to be more turbulent applying the highpower laser, this strategy was appropriate to obtain sound contours. Table 1 details the ranges, in which the process parameters were varied for exposure of the different areas. 
Table 1 Process parameters applied for fabrication of specimens

\begin{tabular}{ll}
\hline Laser power $(\mathrm{W})$ & $150-1000$ \\
Laser scanning speed $\left(\mathrm{mm} \mathrm{s}^{-1}\right)$ & $100-1000$ \\
Hatch distance $(\mathrm{mm})$ & $0.1-1.0$ \\
Layer thickness $(\mu \mathrm{m})$ & $50-150$ \\
\hline
\end{tabular}

In a first step, cylindrical rods with a diameter of $8 \mathrm{~mm}$ and a length of $130 \mathrm{~mm}$ were built with the long axis parallel to the building direction (BD) during processing. Then, specimens for both tensile and creep tests were cut out of the core area, i.e. the area processed by the highpower laser, using electro discharge machining. In the case of tensile specimens, the geometry was dog-bone shaped with final nominal gauge length dimensions of $8 \mathrm{~mm} \times 3 \mathrm{~mm} \times 1.5 \mathrm{~mm}$. Specimens used for creep tests were cylindrical with a diameter of $4 \mathrm{~mm}$ and a length of $6 \mathrm{~mm}$. All specimens were oriented with the loading axis parallel to BD of the initial rods and featured a gauge length processed via the high-power laser only.

Different heat treatments were applied to examine the impact on microstructure and mechanical behaviour. In the first stage, samples were annealed for $1 \mathrm{~h}$ at discrete temperatures ranging from 550 to $1050{ }^{\circ} \mathrm{C}$ followed by air cooling (in the remainder termed according to the temperature applied, e.g. " $550{ }^{\circ} \mathrm{C}$ "). Subsequent ageing followed the standard route as suggested by Special Metals Corporation [25] comprising $8 \mathrm{~h}$ at $720^{\circ} \mathrm{C}$, furnace cooling to $621{ }^{\circ} \mathrm{C}$ and holding for $8 \mathrm{~h}$ followed by air cooling (in the remainder, the conditions are termed according to the temperature applied during prior annealing and the suffix “+ aged", e.g., " $550{ }^{\circ} \mathrm{C}+$ aged"). For comparison, the remaining samples were left in the as-processed condition ("as-processed") or subjected to the ageing heat treatment directly after processing ("direct aged"). To avoid contamination with oxygen, all heat treatments were conducted in vacuum atmosphere.

For Vickers hardness measurements, specimens were ground down to $5 \mu \mathrm{m}$ grit size and tested applying a force of $9.8 \mathrm{~N}$. For each condition, the hardness values were calculated by taking the average of ten indents. Specimens for tensile testing were ground down to $15.3 \mu \mathrm{m}$ grit size and tested using a servo hydraulic testing rig operating in displacement control at a crosshead speed of $2 \mathrm{~mm} \mathrm{~min}^{-1}$. Contacting extensometry was used for recording tensile strains. At least two samples of each condition were tested. Specimens of selected conditions were ground down to 8.4 $\mu \mathrm{m}$ grit size and used for creep tests, which were conducted under constant compressive stress of $725 \mathrm{MPa}$ at $630^{\circ} \mathrm{C}$. For microstructural characterisation via electron backscatter diffraction (EBSD), and X-ray diffraction (XRD), specimens were prepared by grinding down to $5 \mu \mathrm{m}$ grit size and subsequent vibro-polishing for at least $8 \mathrm{~h}$ to obtain a proper surface finish. The EBSD measurements were done with a step size of $4 \mu \mathrm{m}$ in an area of $1 \mathrm{~mm} \times 1 \mathrm{~mm}$ using a Philips XL 40 ESEM TMP scanning electron microscope (SEM) at an acceleration voltage of $20 \mathrm{kV}$. Information on texture in a more comprehensive area was obtained by using an X'pert Pro (Philips) equipped with a $\mathrm{Cu}-\mathrm{K} \alpha$-source working at $45 \mathrm{kV}$ and $40 \mathrm{~mA}$.

In-depth insights were obtained by transmission electron microscopy (TEM) using a Phillips CM200/STEM operating at a nominal voltage of $200 \mathrm{kV}$. For this purpose, specimens were taken from the sample heads and mechanically ground down to $80 \mu \mathrm{m}$ thickness. Electron lucent discs were obtained by twinjet polishing with a perchloric acid solution at $-22{ }^{\circ} \mathrm{C}$ under a potential of $21 \mathrm{~V}$.

An additional energy dispersive spectroscopy (EDS) unit of the XL 40 ESEM TMP was employed for qualitative evaluation of local chemical compositions on the basis of SEM images. For this purpose, specimens used for EBSD were further etched using Kallings etchant. Backscattered electron (BSE) images were taken by an SEM Zeiss Crossbeam 1540 EsB.

\section{Results and discussion}

The microstructure in the as-processed condition is shown in Fig. 1. The grains appear highly elongated towards BD during processing. With a long axis of several hundred microns, the grains are extended over multiple layers proving the occurrence of an epitaxial solidification mode. This mode is typical for SLM and was found for different materials in earlier works, also when processing was conducted with a low-energy laser $[14,16]$. However, the grain aspect ratio is clearly higher when processing is done with a high-power laser, which was also shown by Niendorf et al. for $316 \mathrm{~L}$ stainless steel [12]. Consequently, the factors determining the solidification mechanisms, i.e. the thermal gradient $G$ and solidification velocity $v$, are appropriate for obtaining elongated grains in Inconel 718 as well.

As already indicated by the colour distribution in the EBSD image, the microstructure is characterised by a strong $<001>$ texture with respect to the BD. As described in previous works $[12,17]$, two phenomena are seen to be responsible for this effect: first, a heat flux strongly directed towards the building platform due to high melt pool temperatures and comparably low building platform temperatures; second, a solidification with $<001>$ parallel to the heat flux as typically observed for cubic crystals [26]. This is emphasised by the results obtained by XRD shown in Fig. 1. A very strong $<001>$ texture parallel to $\mathrm{BD}$ is clearly visible. Although slightly weaker, a strong texture is present in directions perpendicular to BD as well. This might be surprising, as cylindrical rods were produced 

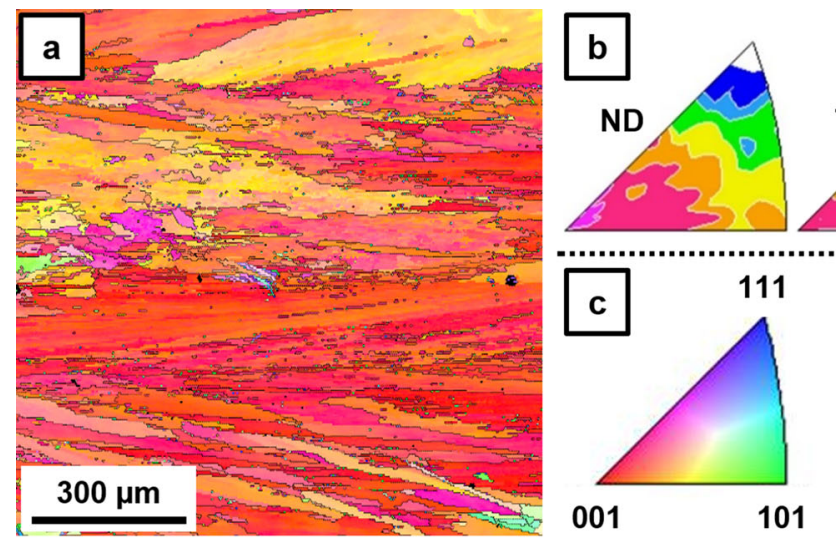
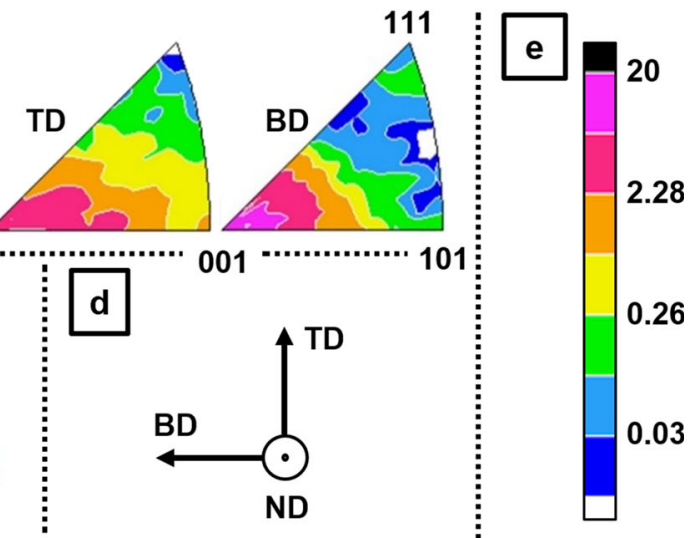

Fig. 1 Inverse pole figure mapping (a) and texture intensities (b) of the as-processed condition obtained by EBSD (a) and XRD (b), respectively. The colour code used for grain orientations in $\mathbf{a}$ is represented by the standard triangle in $\mathbf{c}$. The schematic in $\mathbf{d}$ indicates the spatial directions in a with respect to the building direction (BD), transversal direction (TD) and normal direction (ND). The scale bar in $\mathbf{e}$ reflects the dimensionless value of the texture intensity corresponding to the inverse pole figures obtained by XRD in b (colour figure online)
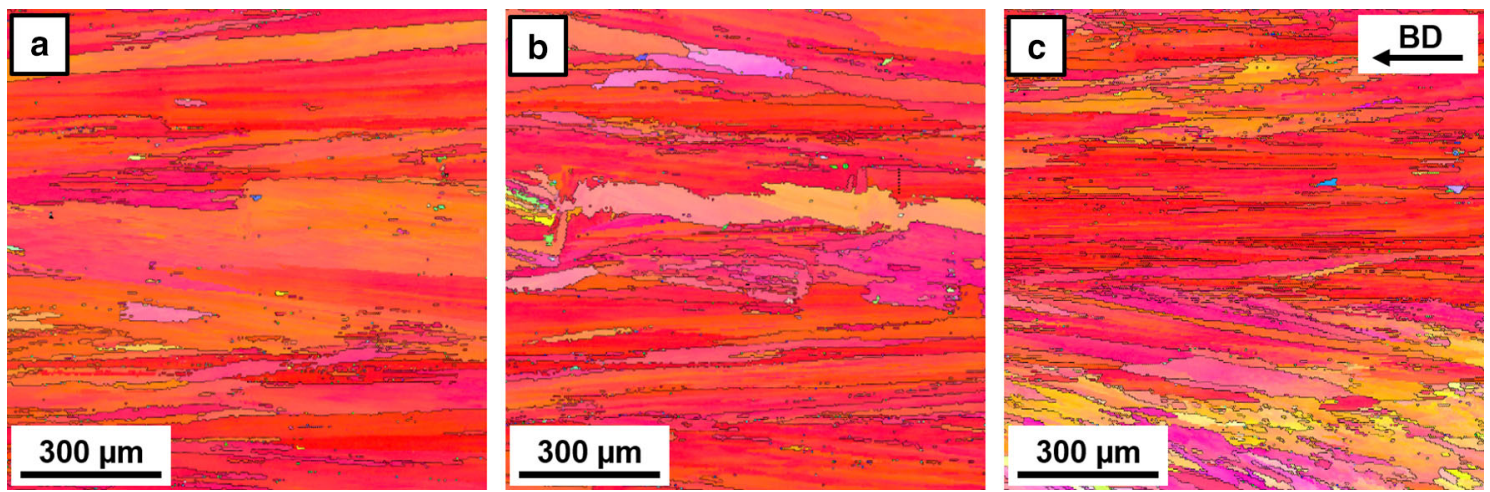

Fig. 2 Inverse pole figure mappings of specimens annealed for $1 \mathrm{~h}$ at $550{ }^{\circ} \mathrm{C}(\mathbf{a}), 700{ }^{\circ} \mathrm{C}(\mathbf{b})$ and $1000{ }^{\circ} \mathrm{C}(\mathbf{c})$. The building direction during processing is indicated by the inset top right and valid for all the three

where the heat can be equally dissipated in all radial directions. However, considering the laser scanning path, which resembles stripes rotated by $90^{\circ}$ in each consecutive layer, the $<001>$ texture in the transversal direction (TD) and normal direction (ND) is reasonable. Clearly, the laser path and laser velocity themselves have a high impact on the heat dissipation and thus $G$ and $v$. This was shown previously in [17] with the example of an AlSiMg10 alloy. Again, the effects can expected to be more pronounced when using the high-power laser, which is supported by the texture intensity distribution for TD and ND in Fig. 1 in comparison with values given in [27] for Inconel 939 processed by a low-energy laser.

By annealing for $1 \mathrm{~h}$ at different temperatures, the grain morphology and texture seem not to be affected, irrespective of the temperature applied. As shown in Fig. 2, for annealing temperatures of 550,700 and $1000{ }^{\circ} \mathrm{C}$, the microstructure still features elongated grains and strong images. The colour code for grain orientations is according to the standard triangle given in Fig. 1 (colour figure online)

texture for the $<001>$ fibre as in the case of the as-processed condition.

Although large residual stresses were reported for many additively processed materials, e.g. in [11, 24, 28], and recrystallisation or weakening of texture was observed after ageing of Ni-base alloys [14, 24, 27], the driving forces in Inconel 718 processed by the high-power laser apparently are not high enough for promoting recrystallisation during 1-h annealing at temperatures of up to $1000{ }^{\circ} \mathrm{C}$. The same is valid for the ageing treatments as well, as no changes in grain morphology and texture were observed (EBSD mappings not shown for the sake of brevity).

Although the microstructural results found by EBSD and XRD do not show any particularities related to the different heat treatments, the hardness measurements clearly revealed a dependency of hardness on the postprocessing heat treatments, as shown in Fig. 3. 


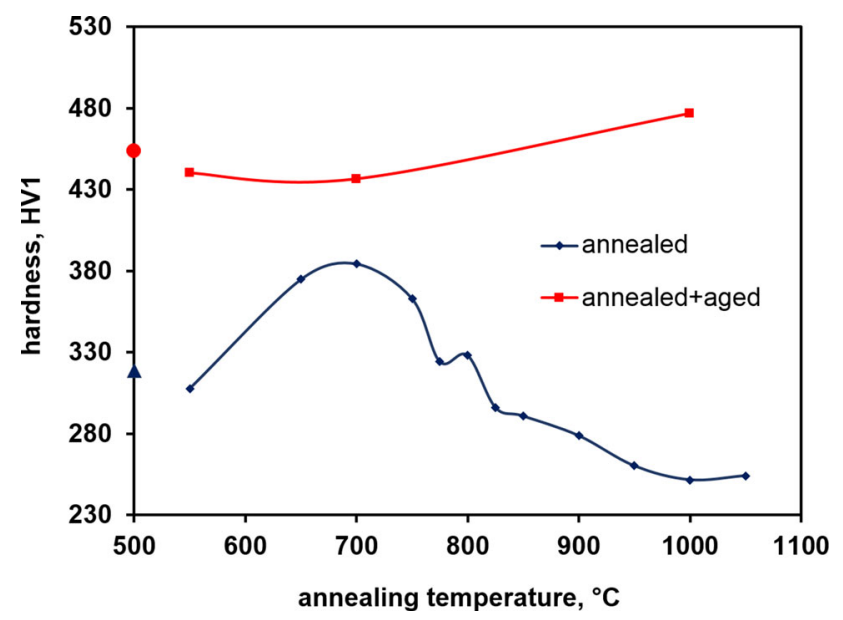

Fig. 3 Vickers hardness in dependence of the applied post-process heat treatment. The markers at the ordinate indicate the hardness of the as-processed (triangle) and the direct-aged condition (circle)

Starting at 320 HV1 directly after processing, the hardness values initially increase with increasing temperatures during 1 -h annealing (lower graph). The maximum is reached at 385 $\mathrm{HV} 1$, when annealed at $700{ }^{\circ} \mathrm{C}$. Higher temperatures apparently lead to a decrease again until at $1000{ }^{\circ} \mathrm{C}$ the lowest hardness values of about $250 \mathrm{HV} 1$ are obtained. Although the hardness level generally is raised by subsequent ageing, the gain in hardness clearly is different in dependency of the temperature of prior 1 -h annealing. The highest absolute value and the highest gain are observed for the $1000{ }^{\circ} \mathrm{C}$ condition, whereas the $700{ }^{\circ} \mathrm{C}$ condition is characterised by the lowest value upon ageing. From this, clear differences in the mechanical performance can be expected.

Results obtained by tensile testing are shown in Fig. 4. Contemplating the solely annealed conditions, the respective stress-strain behaviours are fairly distinctive. By 1-h annealing, the yield strength increases upon annealing at temperatures of 550 and $700{ }^{\circ} \mathrm{C}$. A decrease in yield strength is observed for the $1000{ }^{\circ} \mathrm{C}$ condition. In general, the behaviour shows a reduction of elongation at failure with higher strengths. After ageing, the differences in mechanical behaviour are not pronounced and the relationship between strength and elongation at failure forfeits clarity due to scatter between individual tests. Further tests have to be conducted to allow for statistical evidence and to provide for more definite values. Due to the high number of conditions contemplated, this was clearly out of the scope of this study and, thus, has to be subject of future work. Still, some general trends could be observed. Hence, on average, the relationships between yield strength and post-treatment, shown in the inset in Fig. 4, reveal the highest yield strength of about $1100 \mathrm{MPa}$ for the $1000{ }^{\circ} \mathrm{C}+$ aged condition. The other conditions feature slightly lower yield strengths ranging from 940 to

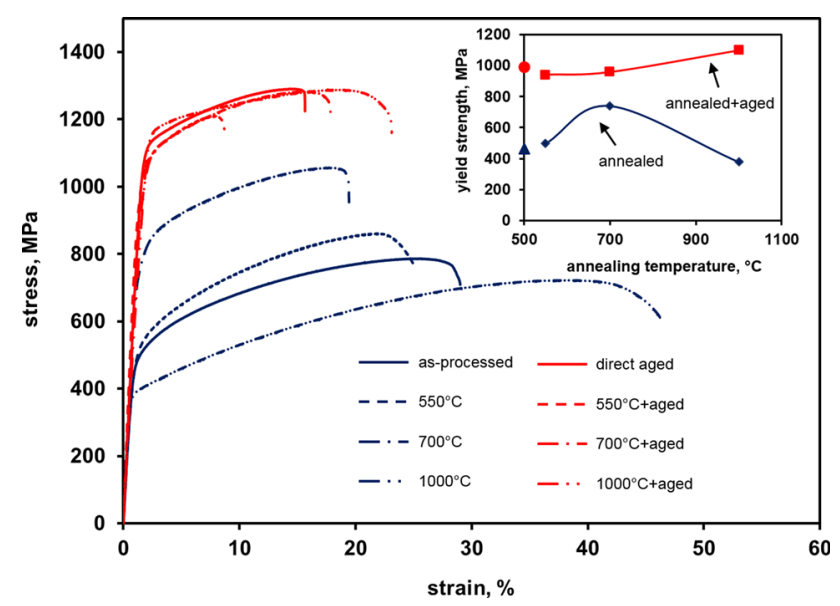

Fig. 4 Tensile stress-strain behaviour of additively manufactured Inconel 718 specimens in dependence of the applied heat treatment. The inset depicts the yield strength as a function of the temperature during 1-h annealing. The yield strength of the as-processed and the direct-aged condition are given directly at the ordinate in shape of a triangle and a circle, respectively

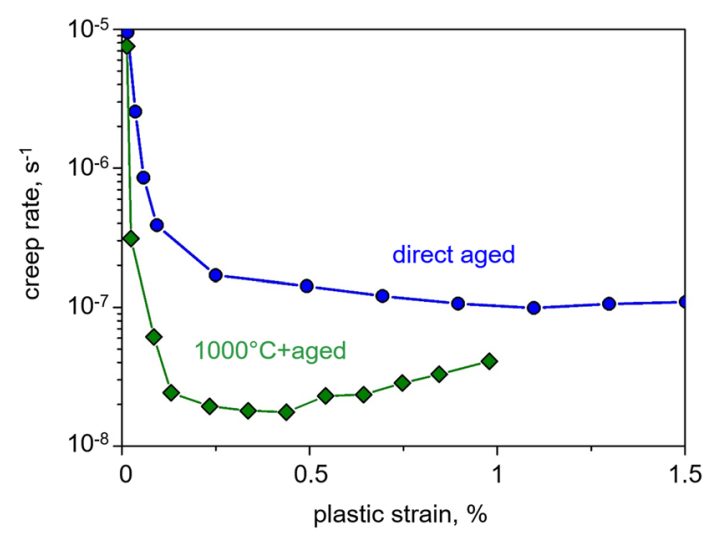

Fig. 5 Creep curves of the direct-aged and $1000{ }^{\circ} \mathrm{C}+$ aged conditions under constant compressive stress of $725 \mathrm{MPa}$ at $630{ }^{\circ} \mathrm{C}$

$990 \mathrm{MPa}$. Remarkable is the perfect correspondence between the curves for the yield strength and hardness in Figs. 3 and 4, respectively.

Due to highest yield strengths, the direct-aged and the $1000{ }^{\circ} \mathrm{C}+$ aged conditions were selected for subsequent creep tests. Although the yield strengths of these conditions are quite similar and the applied compressive stress of $725 \mathrm{MPa}$ is far lower, the difference in creep behaviour is distinct. As can be seen in Fig. 5, the minimum creep rates of both conditions differ about one order of magnitude.

The differences between diverse sample conditions, as revealed by both tensile and creep testing, cannot be explained on the basis of the microstructural results obtained by EBSD as no changes in grain morphology and orientation were observed. Thus, transmission electron microscopy and BSE analyses were conducted to get indepth insights. 
Fig. 6 TEM bright field images revealing the presence of Laves phase particles in the asprocessed condition (a) and after annealing at $700{ }^{\circ} \mathrm{C}$ (b) as indicated by white arrows. During annealing at $1000{ }^{\circ} \mathrm{C}$, Laves particles get partially dissolved (c). Reflexes revealing the incoherent character of the Laves phase found in the asprocessed condition are visible in $\mathbf{d}$. The BSE contrast images in $\mathbf{e}$ and $\mathbf{f}$ illustrate the particle arrangement in the as-built condition as viewed parallel and perpendicular to $\mathrm{BD}$, respectively
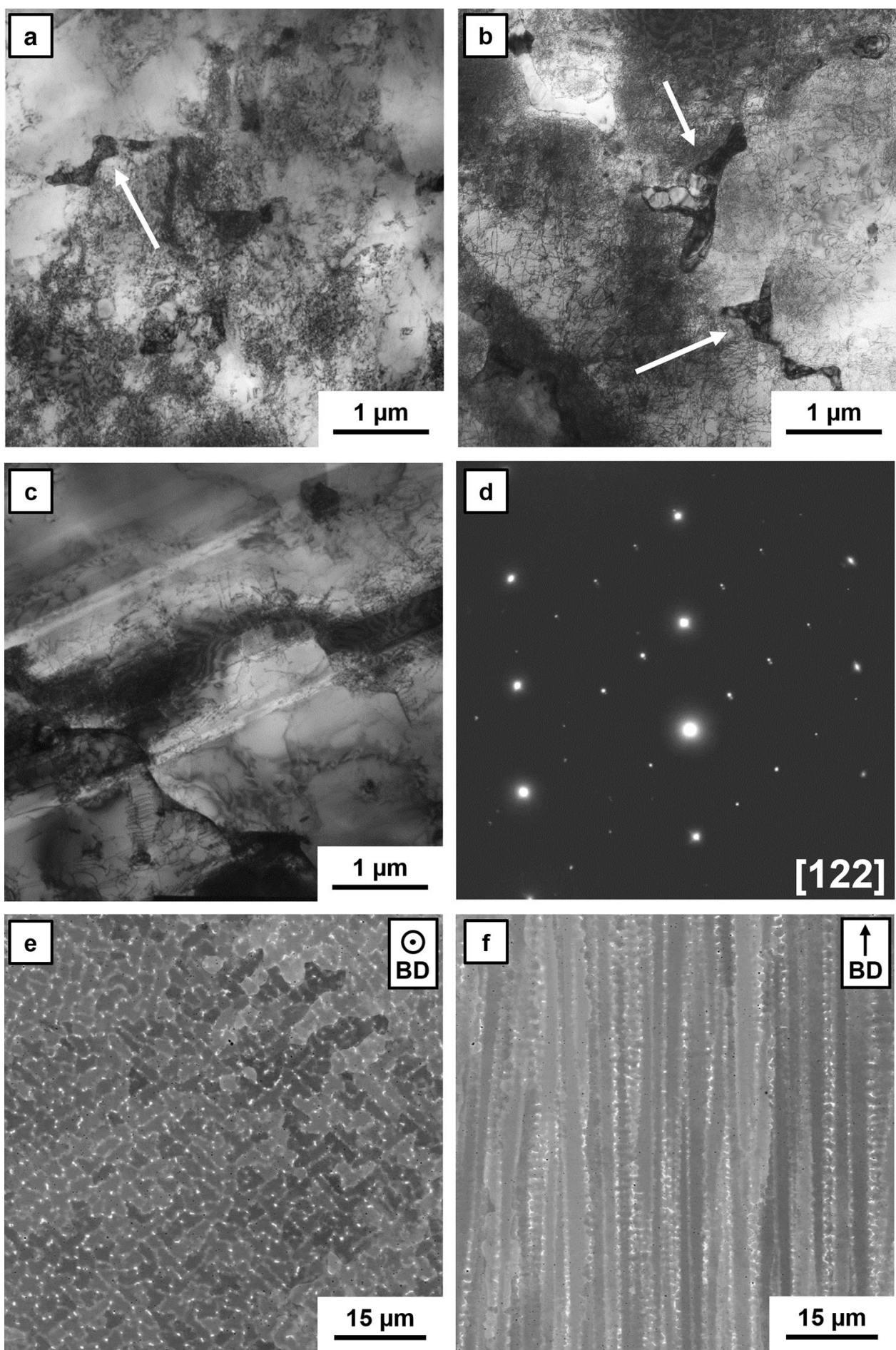

In the as-processed condition and in the 550 and $700{ }^{\circ} \mathrm{C}$ conditions, irregularly shaped particles with dimensions of 1-2 $\mu \mathrm{m}$ were found within the $\gamma$-matrix (only shown for the as-processed condition and the $700{ }^{\circ} \mathrm{C}$ condition in Fig. 6a, b, respectively).

Similarly shaped particles were found in other studies as well, where parts were obtained by laser net shape manufacturing [23] or direct laser fabrication [29]. As in the case of SLM, these processes are characterised by high temperature gradients and rapid solidification. Thus, solidification mechanisms can be assumed to be similar leading to the same kinds of precipitations. Qi et al. in [23] as well as Parimi et al. in [29] identified the particles as Laves phase due to increased amounts of $\mathrm{Nb}$ and Mo. In this study, this was verified by means of EDS point measurements conducted on single particles and in the matrix. Although the 
particles were fairly small and peaks stemming from the surrounding matrix impede an exact measurement, the amounts of $\mathrm{Nb}$ and Mo within the particle were clearly increased. Due to their incoherent character, deducible from the selected area electron diffraction (SAED) pattern in Fig. 6d, these particles are often seen to be detrimental for the mechanical properties in terms of ductility and fatigue resistance $[30,31]$.

However, the occurrence of this phase is seen to be a direct result of processing with the high-power laser, as the formation of Laves phase particles was not observed when processing was conducted at lower energies in [14]. This is in line with results from Parimi et al. [29], who showed an increase in the Laves particle size with higher laser power during direct laser fabrication. Similar phenomena were described in works focusing on processing of Inconel 718 by shaped metal deposition or by welding and were explained by segregation effects during solidification. By increasing the heat input or lowering the cooling rate, the formation of Laves phase was found to be facilitated $[32,33]$. The same mechanisms act in the case of this study. The processing parameters are favourable for the formation of Laves phase, which apparently cannot be avoided when elongated grain morphology and strong $<001>$ texture are desired.

The distribution of the Laves particles is perceptible by BSE contrast images on larger scale (Fig. 6e, f). Apparently, the particles are arranged in arrays on subgrain scale. In other studies, where Ni-base alloys were processed by lowpower SLM, columnar structures of similar size were observed as well and found to be marked by low-angle grain boundaries [14, 27]. However, precipitation of Laves phase particles at these sites was not observed, and the array dimensions were smaller in these studies, which both might be attributable to the lower laser power applied and/or the different chemical composition of the material used in [27].
In Fig. 6c, slip bands, resulting from dislocation movement during tensile testing of the specimen annealed at $1000{ }^{\circ} \mathrm{C}$, are clearly visible in the form of slanting lines. This could not be avoided, although the samples were taken from the barely deformed sample head. However, as no particles are discernible on the small scale, the content of Laves phase particles seems to be affected by annealing. This assumption was confirmed by BSE imaging on larger scale (Fig. 7). Although these images were obtained on aged specimens, it becomes clear that a maximum temperature of $720{ }^{\circ} \mathrm{C}$ is not sufficient for dissolution of Laves particles, whereas the proportion of Laves phase is significantly reduced by annealing at $1000{ }^{\circ} \mathrm{C}$ prior to ageing. Obviously, thermal energy is not sufficient for diffusion of $\mathrm{Nb}$ atoms at temperatures below $1000{ }^{\circ} \mathrm{C}$.

These insights are in line with the results of other researchers [23], who observed remaining Laves particles after annealing and ageing at temperatures of up to $982{ }^{\circ} \mathrm{C}$ and dissolution of the Laves phase after homogenisation for $1 \mathrm{~h}$ at $1093{ }^{\circ} \mathrm{C}$. However, grain growth was observed in the case of the latter due to recrystallisation. This had to be avoided in this study to preserve the textured and elongated grain structure. Apparently, annealing at slightly reduced temperatures of $1000{ }^{\circ} \mathrm{C}$ leads to both reduction of Laves phase content and avoidance of pronounced recrystallisation (cf. Figs. 2c, 7a, b). Still, it has to be considered that Laves phase particles were not completely dissolved by annealing for $1 \mathrm{~h}$ at $1000{ }^{\circ} \mathrm{C}$, and in addition, the process used in [23] was different, possibly resulting in higher residual stresses and, thereby, facilitating recrystallisation.

After ageing, all conditions revealed pronounced presence of finely dispersed precipitates (depicted in Fig. 8a, b only for the conditions $700{ }^{\circ} \mathrm{C}+$ aged and $1000{ }^{\circ} \mathrm{C}+$ aged, respectively). In Fig. 8c, the SAED pattern obtained from the $1000{ }^{\circ} \mathrm{C}+$ aged condition shows reflections
Fig. 7 BSE images revealing different proportions of Laves phase particles $\mathbf{a}$ in the specimen subjected to $720{ }^{\circ} \mathrm{C}$, i.e., the direct-aged condition, and $\mathbf{b}$ in the $1000{ }^{\circ} \mathrm{C}+$ aged condition
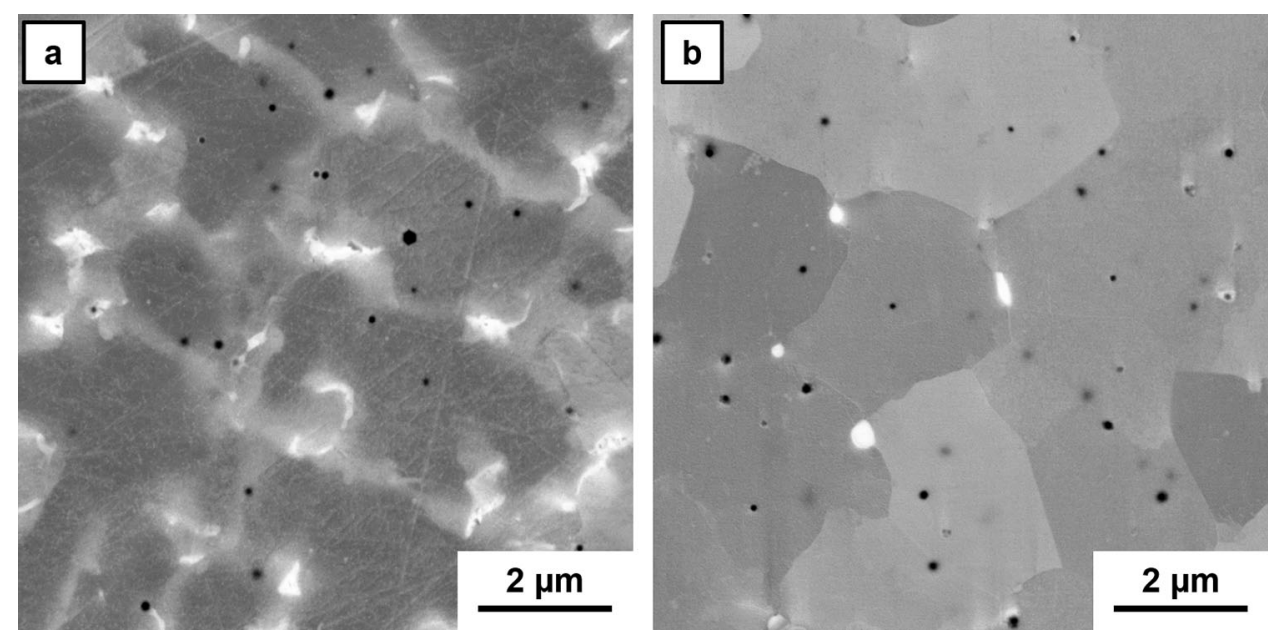

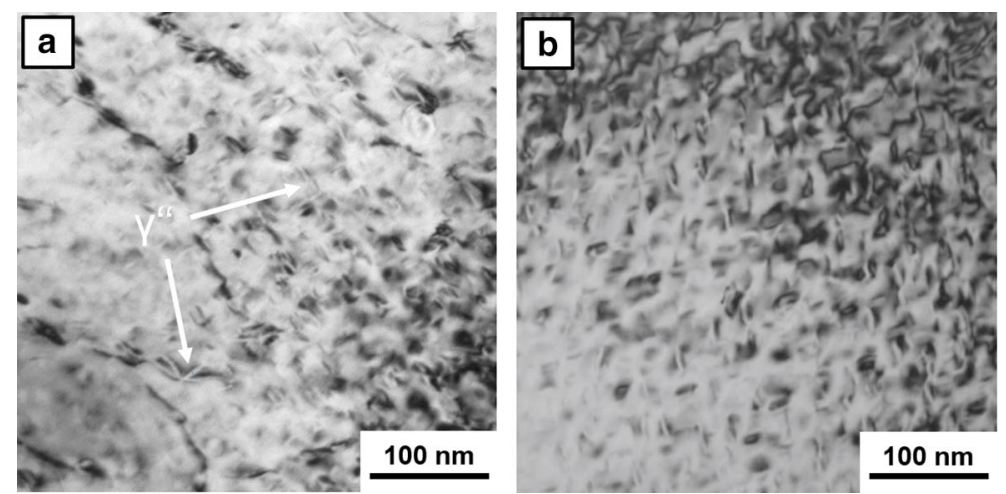

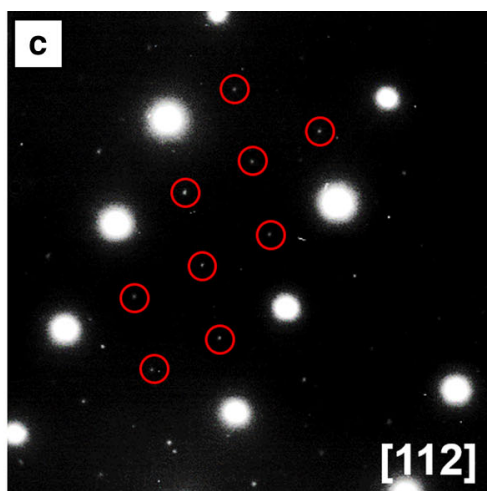

Fig. 8 TEM bright field images showing strain field contrast from lenticular-shaped $\gamma^{\prime \prime}$ precipitations in defined orientations in the $700{ }^{\circ} \mathrm{C}+$ aged (a) and in the $1000{ }^{\circ} \mathrm{C}+$ aged (b) condition.
Superlattice reflections (highlighted by red circles) stemming from the coherent $\gamma^{\prime \prime}$ precipitations are visible in the selected area electron diffraction pattern in $\mathbf{c}$ obtained from $\mathbf{b}$ (colour figure online) stemming from these particles being coherently embedded in the $\gamma$-matrix. The long axis of single particles is found to be about $22 \mathrm{~nm}$, whereas the short axis is $4 \mathrm{~nm}$, leading to an aspect ratio of 5.5. These characteristics are peculiar to the $\gamma^{\prime \prime}$ phase, as typically present in Inconel 718 after ageing treatments and found by many other researchers irrespective of the manufacturing route [14, 23, 34, 35].

In combination with the face-centered cubic $\gamma^{\prime}$ phase with the composition $\mathrm{Ni}_{3}(\mathrm{Al}, \mathrm{Ti}, \mathrm{Nb})$, the body-centered tetragonal $\gamma^{\prime \prime}$ phase, having a $\mathrm{Ni}_{3} \mathrm{Nb}$ composition, accounts for high strength and good creep resistance of Inconel 718 [1]. However, the phases are not discernible straightforward by conventional TEM analyses, as both are coherent to the $\gamma$-matrix and their unit cell parameters are similar resulting in superposition of diffraction pattern. Therefore, great effort was made in many earlier studies to unambiguously discern between these phases [34, 36]. Although $\gamma^{\prime}$ precipitates were not directly observed in this study, the presence of this phase is likely as a physical association between both types is often observed [37].

Differences in volume fractions of the precipitation phases present in the differently heat treated samples cannot be perceived by TEM, since only small areas of each condition were contemplated. However, combining the insights obtained by TEM with the results from BSE images, hardness measurements, tensile testing and creep tests, following assumptions with respect to the formation kinetics of the precipitates and their effect on the mechanical properties can be made: During annealing for $1 \mathrm{~h}$ at $700{ }^{\circ} \mathrm{C}$, which is close to the temperature during ageing treatment, the formation of $\gamma^{\prime}$ and $\gamma^{\prime \prime}$ nuclei is initiated. Due to slightly lower temperatures than in the case of ageing and comparably short time ( $1 \mathrm{~h}$ during annealing vs. $8 \mathrm{~h}$ during ageing), the precipitations were not fully developed and, therefore, underneath the resolution of the TEM used. However, the mechanical behaviour is already affected, as the $700{ }^{\circ} \mathrm{C}$ condition features increased hardness as well as higher yield strength in comparison with the as-processed condition. In the case of the $550{ }^{\circ} \mathrm{C}$ condition, the formation of $\gamma^{\prime}$ and $\gamma^{\prime \prime}$ precipitates is unlikely as the annealing temperature is too low, according to time-temperature-transformation diagrams of Inconel 718 as given in [38]. Still, differences in strain-hardening behaviour in comparison with the as-processed condition can be perceived. In this case, the elevated temperatures during annealing might enable for dislocation movement. Dislocation annihilation eventually occurs, and residual stresses are released resulting in different strain-hardening capability. In terms of ductility, the conditions feature decreased values with increasing yield strength, which is typically observed in many metallic materials. A distinct embrittlement effect of the Laves phase, as known from other studies, e.g. from wrought and cast Inconel 718 in [30], can be deduced by comparing the as-processed material to the condition annealed for $1 \mathrm{~h}$ at $1000{ }^{\circ} \mathrm{C}$. Due to high temperatures in the case of the latter, the Laves phase partially is dissolved, and the formation of other precipitates is impeded resulting in highest ductility of the solutionised condition.

With respect to yield strength, the $1000{ }^{\circ} \mathrm{C}$ condition is clearly inferior to the as-processed condition. Here, two mechanisms have to be taken into account. The Laves particles partially are dissolved, and a rearrangement of dislocations is likely to set in during annealing. Although the exact contribution of each effect to the change in yield strength cannot be defined on the basis of data presented here, both surely have an impact on dislocation mobility and, thus, on yield strength.

In course of ageing, the major formation of primary strengthening phases $\gamma^{\prime}$ and $\gamma^{\prime \prime}$ occurs. Still, the conditions $550{ }^{\circ} \mathrm{C}+$ aged and $700{ }^{\circ} \mathrm{C}+$ aged are characterised by lower yield strength and hardness than the directly aged condition. Thus, in the case of the former conditions, the heat treatment at temperatures lower than the temperature 
during subsequent ageing might have resulted in detrimental formation of ill-defined particles of the strengthening phases, eventually leading to the reduced yield strength. However, due to only small differences in overall annealing time and temperatures between the directly aged and the priorly 1-h annealed conditions, differences in precipitation size or morphology were not perceptible by TEM in the case of this study. However, in other studies $[34,37]$, prolongation of annealing time was reported to lead to particle coarsening concomitant with a reduction of yield strength. Hence, similar effects are seen to be active in this study.

The best results in terms of yield strength, ductility and creep strength were observed for the $1000{ }^{\circ} \mathrm{C}+$ aged condition. Especially, the large difference in creep performance between the direct-aged and $1000{ }^{\circ} \mathrm{C}+$ aged conditions supports the importance of solution annealing for obtaining a proper high-temperature performance. This is clearly attributable to the partial dissolution of the Laves phase taking place during solutionizing. As the Laves phase depletes large amounts of $\mathrm{Nb}$, which, therefore, is not available for precipitation of the primary strengthening phases $\gamma^{\prime}$ and $\gamma^{\prime \prime}$ during ageing, conditions featuring high amounts of Laves phase are reported to suffer from both reduced yield strength and poor ductility after ageing [30, 31, 39]. However, it has to be noted that temperatures during solutionizing have to be as low as possible to avoid recrystallisation and concomitant reduction of yield strength, as shown in [23]. In accordance with the merely annealed conditions, the ductility is reduced in the aged specimens, which feature pronounced presence of the Laves phase, i.e. the $500{ }^{\circ} \mathrm{C}+$ aged and the $700{ }^{\circ} \mathrm{C}+$ aged condition. However, although this trend is obvious, it has to be noted that only two samples for each condition were tested, and no definite values can be given due to the scatter observed.

Comparing quantitatively strength and ductility after ageing to values of traditionally cast and wrought materials, e.g. as given in [30, 40], slightly higher yield strengths can be observed for wrought materials, whereas cast material reveals clearly lower performance. In terms of ductility, the material processed by SLM outperforms the other manufacturing routes. Clearly, yield strength and ductility are not only determined by morphology and distribution of precipitates. The grain size as described by the Hall-Petch relationship and the presence of the structures on subgrain scale play an important role as well. In the case of the specimens examined in this study, the effective grain size, i.e. the grain long axis along the building direction, is in the range of several $100 \mu \mathrm{m}$ and thus similar to cast and significantly higher than in wrought material [40].

Contemplating the creep performance, it has to be noted that on the one hand, the microstructural features induced by the high-power laser, i.e. the columnar and highly textured grain structure, are not effective at temperatures far below $1000{ }^{\circ} \mathrm{C}$. On the other hand, such high temperatures are clearly out of the operating range of Inconel 718. At temperatures applied in this study, i.e. at about $630{ }^{\circ} \mathrm{C}$, the creep performance is dominated by the same microstructural features as in the case of tensile testing. Thus, besides the formation of proper precipitations, small grain sizes are desirable to obtain a high creep strength. Consequently, the creep performance of the additively manufactured Inconel 718 can, as in the case of tensile testing, assumed to be competitive to wrought material. However, a direct comparison is the subject of a follow-up study.

Clearly, further studies will be necessary to fully evaluate the impact of high-power SLM processing on the performance of Ni-base alloys. Tensile tests and fatigue experiments at temperatures of up to $630{ }^{\circ} \mathrm{C}$ have to be conducted to establish additively manufactured Inconel 718 for actual applications. Another aspect is the effect of directly created cooling channels, i.e. holes manufactured within the SLM process, on the surrounding microstructure and, hence, on the mechanical properties. Finally, high-power processing has to be extended towards other high-temperature alloys enabling for illustrating the suitability of process-induced columnar and textured microstructures for applications at temperatures of more than $1000{ }^{\circ} \mathrm{C}$.

\section{Summary and conclusions}

High-power selective laser melting was employed for processing of Inconel 718 to induce a columnar and highly textured microstructure. After processing, the specimens were subjected to different heat treatments. The grain structure and precipitations were characterised via EBSD, BSE and TEM. Mechanical characterisation was conducted in the form of hardness measurements, tensile testing and high-temperature creep tests. The main findings can be summarised as follows:

- The as-processed microstructure features elongated grains with a strong $<001>$ texture with respect to the building direction. In addition, incoherent Laves phase particles were found concomitant with subgrain structures parallel to BD.

- Annealing for $1 \mathrm{~h}$ at temperatures of 550 and $700{ }^{\circ} \mathrm{C}$ did not lead to dissolution of Laves phase particles, and no strengthening phases could be proven via TEM. Still, mechanical data revealed increased hardness and yield strength in comparison with the as-processed condition, leading to the assumption that recovery and precipitation of strengthening phases, respectively, have already initiated. 
- Annealing for $1 \mathrm{~h}$ at $1000{ }^{\circ} \mathrm{C}$ led to partial dissolution of the Laves phase, while rearrangement of dislocations is seen to lead to a recovered microstructure. The concurrence of these effects is responsible for the lowest hardness and yield strength observed in this study.

- After ageing, a significant amount of the strengthening $\gamma^{\prime \prime}$ phase was identified via TEM in all conditions. $\gamma^{\prime}$ particles are likely to occur simultaneously, but could not be unambiguously identified.

- Higher strengths and lower elongations at failure are observed after ageing. Remnant amounts of the Laves phase particles are seen to impede the formation of the strengthening phases and, therefore, lead to inferior mechanical performance upon low-temperature annealing. This became evident by comparing the creep performance of the direct-aged and $1000{ }^{\circ} \mathrm{C}+$ aged conditions.

- None of the heat treatments conducted led to recrystallization. Thus, the desired texture and grain morphology induced by the high-power laser were preserved.

- The mechanical performance in terms of yield strength and elongation at failure of the SLM processed conditions is almost equal to values obtained by wrought material and clearly better in comparison with cast material. A comparison with conventionally manufactured Ni-based superalloys under creep has to be drawn after testing at higher temperatures to prove a positive effect of a microstructure featuring columnar and textured grains.

The insights illustrate the general feasibility of producing Ni-based parts featuring a strong $<001>$ texture and grains elongated along the building direction. By applying post-processing in the form of $1-\mathrm{h}$ annealing at $1000{ }^{\circ} \mathrm{C}$ and subsequent standard ageing treatment, the desired microstructural features survive, detrimental Laves phase particles are partially dissolved and strengthening phases are formed. The resulting mechanical performance under tensile load and creep at $630{ }^{\circ} \mathrm{C}$ is seen to be competitive to conventionally processed Inconel 718 .

Acknowledgments TN acknowledges support by Deutsche Forschungsgemeinschaft under Contract No. NI1327/7-1. Additional financial support under Contract No. NI1327/4-1 is also acknowledged. $\mathrm{H}$. Hüsing is thanked for assistance in conducting tensile tests and hardness measurements.

\section{References}

1. Sims CT, Stoloff NS, Hagel WC (1987) Superalloys II, 1st edn. Wiley-Interscience, New York
2. Bürgel R, Maier H, Niendorf T (2011) Handbuch Hochtemperatur-Werkstofftechnik, 4th edn. Vieweg + Teubner, Wiesbaden

3. Wang Z, Rajurkar K, Fan J, Lei S, Shin Y, Petrescu G (2003) Hybrid machining of Inconel 718. Int $\mathrm{J}$ Mach Tool Manu 43(13):1391-1396. doi:10.1016/S0890-6955(03)00134-2

4. Kaynak Y (2014) Evaluation of machining performance in cryogenic machining of Inconel 718 and comparison with dry and MQL machining. Int J Adv Manuf Technol 72(5):919-933. doi:10.1007/s00170-014-5683-0

5. Ezugwu EO (2005) Key improvements in the machining of difficult-to-cut aerospace superalloys. Int J Mach Tool Manu 45(1213):1353-1367. doi:10.1016/j.ijmachtools.2005.02.003

6. Loria EA (1988) The status and prospects of alloy 718. JOM 40(7):36-41

7. Appa Rao G, Srinivas M, Sarma DS (2006) Influence of modified processing on structure and properties of hot isostatically pressed superalloy Inconel 718. Mater Sci Eng, A 418(1-2):282-291. doi:10.1016/j.msea.2005.11.031

8. Murr LE, Gaytan SM, Ramirez DA, Martinez E, Hernandez J, Amato KN, Shindo PW, Medina FR, Wicker RB (2012) Metal fabrication by additive manufacturing using laser and electron beam melting technologies. J Mater Sci Technol 28(1):1-14. doi:10.1016/S1005-0302(12)60016-4

9. Emmelmann C, Sander P, Kranz J, Wycisk E (2011) Laser additive manufacturing and bionics: redefining lightweight design. Phys Procedia 12:364-368. doi:10.1016/j.phpro.2011.03. 046

10. Osakada K, Shiomi M (2006) Flexible manufacturing of metallic products by selective laser melting of powder. Int J Mach Tool Manu 46(11):1188-1193. doi:10.1016/j.ijmachtools.2006.01.024

11. Leuders S, Thöne M, Riemer A, Niendorf T, Tröster T, Richard HA, Maier H (2013) On the mechanical behaviour of titanium alloy TiAl6V4 manufactured by selective laser melting: fatigue resistance and crack growth performance. Int $\mathrm{J}$ Fatigue 48:300-307. doi:10.1016/j.ijfatigue.2012.11.011

12. Niendorf T, Leuders S, Riemer A, Richard HA, Tröster T, Schwarze D (2013) Highly anisotropic steel processed by selective laser melting. Metall Mater Trans B 44(4):794-796. doi:10.1007/ s11663-013-9875-z

13. Holzweissig MJ, Taube A, Brenne F, Schaper M, Niendorf T (2015) Microstructural characterization and mechanical performance of hot work tool steel processed by selective laser melting. Metall Mater Trans B 46(2):545-549. doi:10.1007/s11663-0140267-9

14. Amato KN, Gaytan SM, Murr L, Martinez E, Shindo PW, Hernandez J, Collins S, Medina F (2012) Microstructures and mechanical behavior of Inconel 718 fabricated by selective laser melting. Acta Mater 60(5):2229-2239. doi:10.1016/j.actamat. 2011.12.032

15. Niendorf T, Brenne F (2013) Steel showing twinning-induced plasticity processed by selective laser melting - an additively manufactured high performance material. Mater Charact 85:57-63. doi:10.1016/j.matchar.2013.08.010

16. Thijs L, Montero S, Maria L, Wauthle R, Xie Q, Kruth J, van Humbeeck J (2013) Strong morphological and crystallographic texture and resulting yield strength anisotropy in selective laser melted tantalum. Acta Mater 61(12):4657-4668. doi:10.1016/j. actamat.2013.04.036

17. Thijs L, Kempen K, Kruth J, van Humbeeck J (2013) Finestructured aluminium products with controllable texture by selective laser melting of pre-alloyed AlSi10 Mg powder. Acta Mater 61(5):1809-1819. doi:10.1016/j.actamat.2012.11.052

18. Atlas Specialty Metals (2004) Atlas 316L hollow bar. www. atlassteels.com.au/documents/Atlas316L_hollow_bar.pdf. Accessed 9 Dec 2015 
19. Thijs L, Verhaeghe F, Craeghs T, van Humbeeck J, Kruth J (2010) A study of the microstructural evolution during selective laser melting of Ti-6Al-4V. Acta Mater 58(9):3303-3312. doi:10.1016/j.actamat.2010.02.004

20. Niendorf T, Brenne F, Schaper M (2014) Lattice structures manufactured by SLM: on the effect of geometrical dimensions on microstructure evolution during processing. Metall Mater Trans B 45(4):1181-1185. doi:10.1007/s11663-014-0086-Z

21. Gäumann M, Henry S, Cléton F, Wagnière J, Kurz W (1999) Epitaxial laser metal forming: analysis of microstructure formation. Mater Sci Eng, A 271(1-2):232-241. doi:10.1016/S09215093(99)00202-6

22. Niendorf T, Leuders S, Riemer A, Brenne F, Tröster T, Richard HA, Schwarze D (2014) Functionally graded alloys obtained by additive manufacturing. Adv Eng Mater 16(7):857-861. doi:10. 1002/adem.201300579

23. Qi H, Azer M, Ritter A (2009) Studies of standard heat treatment effects on microstructure and mechanical properties of laser net shape manufactured INCONEL 718. Metall Mat Trans A 40(10):2410-2422. doi:10.1007/s11661-009-9949-3

24. Liu F, Lin X, Yang G, Song M, Chen J, Huang W (2011) Microstructure and residual stress of laser rapid formed Inconel 718 nickel-base superalloy. Opt Laser Technol 43(1):208-213. doi:10.1016/j.optlastec.2010.06.015

25. Special Metals Corporation (2007) Inconel alloy 718. http:// www.specialmetals.com/documents/Incone1\%20alloy\%20718.pdf. Accessed 9 Dec 2015

26. Gäumann M, Bezençon C, Canalis P, Kurz W (2001) Singlecrystal laser deposition of superalloys: processing-microstructure maps. Acta Mater 49(6):1051-1062. doi:10.1016/S13596454(00)00367-0

27. Kanagarajah P, Brenne F, Niendorf T, Maier H (2013) Inconel 939 processed by selective laser melting: effect of microstructure and temperature on the mechanical properties under static and cyclic loading. Mater Sci Eng, A 588:188-195. doi:10.1016/j. msea.2013.09.025

28. Shiomi M, Osakada K, Nakamura K, Yamashita T, Abe F (2004) Residual stress within metallic model made by selective laser melting process. CIRP Ann Manuf Techn 53(1):195-198. doi:10. 1016/S0007-8506(07)60677-5

29. Parimi LL, Ravi GA, Clark D, Attallah MM (2014) Microstructural and texture development in direct laser fabricated IN718. Mater Charact 89:102-111. doi:10.1016/j.matchar.2013.12.012
30. Schirra JJ, Caless RH, Hatala RW (1991) The effect of laves phase on the mechanical properties of wrought and cast + HIP Inconel 718. Loria EA (ed) Proceedings of superalloys 718, 625 and various derivatives. TMA, Warrendale

31. Janaki Ram GD, Venugopal Reddy A, Prasad Rao K, Reddy GM, Sarin Sundar JK (2005) Microstructure and tensile properties of Inconel 718 pulsed Nd-YAG laser welds. J Mater Process Technol 167(1):73-82. doi:10.1016/j.jmatprotec.2004.09.081

32. Radhakrishna C, Prasad Rao K (1997) The formation and control of Laves phase in superalloy 718 welds. J Mater Sci 32(8):1977-1984

33. Clark D, Bache MR, Whittaker MT (2010) Microstructural characterization of a polycrystalline nickel-based superalloy processed via tungsten-intert-gas-shaped metal deposition. Metall Mater Trans B 418(6):1346-1353. doi:10.1007/s11663-0109410-4

34. Kulawik K, Buffat PA, Kruk A, Wusatowska-Sarnek AM, Czyrska-Filemonowicz A (2015) Imaging and characterization of $\gamma^{\prime}$ and $\gamma^{\prime \prime}$ nanoparticles in Inconel 718 by EDX elemental mapping and FIB-SEM tomography. Mater Charact 100:74-80. doi:10.1016/j.matchar.2014.12.012

35. Özgün Ö, Gülsoy HÖ, Yılmaz R, Fındık F (2013) Microstructural and mechanical characterization of injection molded 718 superalloy powders. J Alloys Compd 576:140-153. doi:10.1016/j.jall com.2013.04.042

36. Dubiel B, Kruk A, Stepniowska E, Cempura G, Geiger D, Formanek P, Hernandez J, Midgley P, Czyrska-Filemonowicz A (2009) TEM, HRTEM, electron holography and electron tomography studies of $\gamma^{\prime}$ and $\gamma^{\prime \prime}$ nanoparticles in Inconel 718 superalloy. J Microsc 236(2):149-157

37. Sundararaman M, Mukhopadhyay P, Banerjee S (1992) Some aspects of the precipitation of metastable intermetallic phases in INCONEL 718. Metall Trans A 23(7):2015-2028

38. Donachie MJ, Donachie SJ (2002) Superalloys, 2nd edn. ASM International, Materials Park

39. Gordine J (1971) Some problems with welding Inconel 718. Weld J 50:480-484

40. Appa Rao G, Kumar M, Srinivas M, Sarma DS (2003) Effect of standard heat treatment on the microstructure and mechanical properties of hot isostatically pressed superalloy Inconel 718. Mater Sci Eng, A 355(1-2):114-125. doi:10.1016/S09215093(03)00079-0 